IBIMA Publishing

Journal of Enterprise Resource Planning Studies

http://www.ibimapublishing.com/journals/JERPS/jerps.html

Vol. 2012 (2012), Article ID 731113, 17 pages

DOI: $10.5171 / 2012.731113$

Research Article

\title{
Towards the Success of ERP Systems: Case Study in Two Moroccan Companies
}

\author{
Brahim Bighrissen ${ }^{1}$, El Mehdi Ettamiri ${ }^{1}$ and Chihab Cherkaoui ${ }^{2}$ \\ ${ }^{1}$ SIC Team Research, ENCG, Agadir - Morocco \\ ${ }^{2}$ IRF-SIC Laboratory, ENCG \& Faculty of Sciences, Agadir - Morocco
}

Received 9 October 2012; Accepted 20 October 2012; Published 30 December 2012

Academic Editor: Yudi Fernando

\begin{abstract}
For over a decade, ERP systems in Morocco have shown a significant increase. Companies make large investments in these scale systems in order to anticipate positive impacts on their organization. Measuring ERP systems success becomes an important criterion for the stakeholders in justifying the associated investment. In this paper, we will examine the success of these systems by using a qualitative research method based on a case study approach. We will provide an insight into how two Moroccan organizations perceive the success of their ERP systems. Findings indicated that Information, system quality and net benefits are the three main dimensions of success.
\end{abstract}

Keywords: Enterprise Resource Planning (ERP), Information Technologies (IT), ERP success, Moroccan organization, case study approach.

\section{Introduction}

The information has generated a deficit that arises from the imperfect data available, the finiteness of treatment and the ambiguity of interpretations available to the decision maker. Many organizations have begun to realize the importance of the data and information they create. It is very difficult today to believe an organization without pertinent information. Indeed, all business functions (accounting, management control, marketing, sales, production, purchasing, human resources, maintenance, or research, etc.) are now covered by an information system (Brasseur, 2005). Everyone is affected by the data and information quality (Loshin, 2001).
With incorrect or incomplete information for example, activity indicators may deviate from reality and lead to inappropriate decisions. In addition, with the expansion of the Internet, the image of the company may be impaired, particularly if the information published is not updated. This kind of problem is usually caused by the proliferation of software applications, their heterogeneity and the rising cost of maintenance. To avoid these problems, companies try to move from a functional organization to a customer-oriented process method. This new model requires the integration of key business processes and the setting up of a coherent information system ensuring the uniqueness of the information and the ability to access it from all the functions of the company. All these aspects are captured by ERP systems.

Copyright (C) 2012 Brahim Bighrissen, El Mehdi Ettamiri and Chihab Cherkaoui. This is an open access article distributed under the Creative Commons Attribution License unported 3.0, which permits unrestricted use, distribution, and reproduction in any medium, provided that original work is properly cited. Contact author: Brahim Bighrissen E-mail: bighrissen_consultant@yahoo.fr 
An Enterprise Resource Planning (ERP) system is an integrated computer application used to manage both internal and external resources of an organization. ERP systems are based on a series of integrated software modules and a single database. The database collects data from many applications and re-injects it into various applications that can handle almost all the internal activities of the organization. When a new process generates new data, it is immediately reusable by other business processes. An ERP implies the concept of extended organization, which stresses the interdependence between organizations, including their coordination and synchronization. This interdependence is to improve the quality of services offered to customers, their efficiency and productivity. ERP systems also allow the integration of various business functions that provide, to each other, data and information.

Many approaches of ERP systems success are presented in the literature. Some of these works present an integrated model of success. Others consider end users satisfaction or utilization or benefits as a measure of success of these systems.

This paper aims to study the perception of managers regarding ERP systems in Two Moroccan organizations. We will begin by presenting some recent trends of the ERP systems and a synthesis of literature on the main ERP success models. In the second part of this paper, we will discuss some empirical evidence of managers' perception regarding ERP systems success in Two Moroccan companies using a qualitative approach based on a case study.

\section{Recent Trends of ERP Systems}

In this section, we present some definitions of ERP systems, the architecture of their technology, some implementation Challenges and finally, we will describe the status of ERP systems in Morocco.

\section{ERP: An Approach of the Definition}

Concerning the definition of what is an ERP, it is important to note that there is no consensus about the used terminology, and there are several definitions in the literature. Firstly, we can say that the term ERP comes from the English expression "Enterprise Resource Planning" which means a tool or a methodology used to manage internal and external resources. Relating to the most specific definitions in the field, an ERP is sometimes defined as a software application, sometimes as a package, as a computer-based application or as a system. Even if the terms designate specific concepts, they are often used interchangeably. Dubarry and Bauvais (1999) have focused its definition on the fact that the ERP system is both an Information Technology System and a subset of the Information Systems (IS). For these authors, an ERP allows a comprehensive management of a company including human resources management, accounting and financial management, sales management, management of procurement, production management and logistics management. Pérotin (2002) present a more synthetic and abstract definition which presents ERPs as "software applications that are customizable and modular designed to integrate and optimize the business processes by providing a single and coherent repository and based on standard business rules". Shang and Seddon (2002) talk about Enterprise System Software (ESS) which consists principally of enterprise resource planning (ERP) and customer relationship management (CRM). According to Chapman and Chua (2000), "an ERP system is an integrated software system that manages the mainstreams operations of an organization. ERP is often defined as a standardized packaged software designed to integrate the entire value chain in the organization".

In short, although the terminology differs from one author to another, the common sense shows that the ERP enables organizations to integrate business processes and functions, and supply with real time information to manage their resources in a better way (both the internal and external) and to improve their decision making process. 


\section{ERP: A Technological Point of View}

One of the main characteristics of an ERP system is the centralization of all data from the business functions of an organization in a single unified relational database. An ERP includes a set of modules that cover all the processes of an organization.

Typically, an ERP system can either reside on a centralized server or be distributed across modular hardware and software units that provide "services" and communicate on a local area network. The distributed design allows a business to assemble modules from different vendors without the need for the placement of multiple copies of complex and expensive computer systems in areas which will not use their full capacity.

\section{The Implementation Challenges}

The implementation of ERP solutions in an organization is not only to install a software in the traditional way, but changing the structure and the management of the whole organization, implying a need to take into account a pipeline project change. Indeed the establishment of an ERP strategy requires structural changes, skills and behaviors.

The deployment of an ERP system can involve considerable business process analysis, employee retraining, and new work procedures. Several researchers have developed different models for ERP implementations. For instance, Parr and Shanks (2000) introduced a model of three phases: planning, project and enhancement. Other studies such as the one done by Ross (1999) illustrates that a road card of an ERP implementation consists of five stages: design, implementation, stabilization, continuous improvement and transformation. Implementing an ERP system is generally an extensive challenge, with a typical ERP implementation taking anywhere from one to five years (Poston and Grabski, 2001). The authors add that the performance of the organization will get worse before it gets better. Organizations are expected to encounter the resistance throughout the stages of ERP implementation.

The best practices (SAP, 2010) indicate that a successful implementation can force an organization to revalue its business practices and its processes and to concentrate on clearly definite objectives. To conclude, organizations have to be vigilant enough when it comes to the question of implementing an ERP system. The implementation of ERP is a complex process that requires a new approach to project management and it is time consuming, it may take generally four to five years.

\section{ERP Systems Adoption in Moroccan Organizations}

In Morocco, ERP market is in full extension, the first major ERP projects were initiated in 1995. A multitude of European and American ERP vendors have settled on the market whose mission is to support the Moroccan companies to implement this type of project. Large companies have taken the step in adopting this technology.

In a survey of 61 largest Moroccan companies conducted in 2010 by the consulting firm called Capital consulting, more than $50 \%$ of the sample is focused on SAP and ORACLE with $41 \%$ for SAP and $18 \%$ for Oracle. Over $12 \%$ of companies use ERP systems such as DYNAMICS, JDE with almost equivalent proportions.

\section{ERP System Success: Definition and Models}

In the literature, various models have been used to measure ERP system success. Before describing the different models, a definition of the notion of success of ERP system will be exposed.

\section{ERP System Success Definition}

ERP system success is a very hard notion to define, giving the fact that there is no consensus regarding its definition. Since the notion of success used in IS domain is equivalent to IS effectiveness (Delone and Mclean, 1992). Thong et al (1996) defined 
IS effectiveness as the extent to which an information system actually contributes to achieving organizational goals. ERP system is a kind of IS, its success depends on the degree of contribution to achieving organizational goals.

Markus and Tanis (2000) defined the success as best outcome that the organization could achieve with enterprise systems, given its business situation, measured against a portfolio of project, early operational, and longer-term business results metrics.

\section{ERP System Success Models}

We present here the main models discussing the success of ERP system.

\section{Mclean and Delone Model $(1992,2003)$}

Based on the work of Shannon and Weaver (1949) and Mason (1978), Delone and Mclean (1992) developed a model which relates six factors or dimensions of success which are the information quality, system quality, system use, user satisfaction, individual impact and organizational impact. This model has been adapted and developed by several researchers like Pitt et al. (1995), and criticized by others, especially by Seddon (1997).

Delone and McLean updated their original model ten years after its release in order to highlight and respond to criticism. In 2003, the authors have extended their first model. They added the "quality of service" as the third dimension determining the use and satisfaction of users and the "intent to use" as the fourth. Individual and organizational impacts are grouped into "net benefits".

It is important to give some definitions of main dimensions of the model as they are accepted in the literature:

- Information Quality: Although the meaning of data and information are different, lee et al. (2002) do not make this distinction and use the term data quality to refer to information quality. It is defined as data that is for use by data consumers (Wang and Strong, 1996).They developed a framework of four information quality (IQ):

- Intrinsic IQ: It means that the information have quality in its own right, it refers to accuracy, objectivity, believability and reputation.

- Contextual IQ: It highlights the requirements that information quality must consider within the context of the task at hand. Value added, relevancy, timeliness, completeness and appropriate amount of information are the dimensions of this category.

- Representational IQ: It relates to format aspects. It consists of interpretability, ease of understanding, representational consistency and concise representation.

- Accessibility IQ: It emphasizes the role played by IT which provide and store information. It consists of accessibility and access security.

- System Quality: It is defined as the level of technical efficiency of the system. (Mclean and Delone, 1992). Nelson et al. (2005) identify five key measures:

- Accessibility: It refers to the degree to which a system and the information it contains can be accessed with relatively low effort.

- Reliability: It relates the dependability of a system over time.

- Response Time: It refers to the degree to which a system offers quick (or timely) responses to requests for information or action.

- Flexibility: It relates to the degree to which a system can adapt to a variety of user needs and to changing conditions.

- Integration: It represents the degree to which a system facilitates the combination of information from 
various sources to support business decisions.

- Service Quality: It involves the overall support delivered by the service provider, and applies regardless of whether this support is delivered by the IS department. (Delone and Mclean, 2003). Pett et al (1995) have used an instrument of five dimensions to assess IS service quality (Tangibles, Reliability, Responsiveness, Assurance, Empathy).

- User Satisfaction: It is defined as the IS end-user's overall affective and cognitive evaluation of the pleasurable level of consumption related fulfillment experienced with IS. (Au et al., 2002). Doll and Torkzadeh (1988) have used an IS end-user satisfaction instrument called evaluation End-User Computing Satisfaction (EUCS).

- Intention to Use: It means the intent to employ the IS in the future. According to Petter and al. (2008), intention to use is generally an individual level construct. It is not a concept that is consistent with studies employing an organizational unit of analysis. So they consider both intention to use and other measures of system use as the same construct.

- System Use: It is the degree and manner in which staff and customers utilize the capabilities of an information system. For example: amount of use, frequency of use, nature of use, appropriateness of use, extent of use, and purpose of use. (Petter et al., 2008) .System use as a success variable is rejected when it is mandatory. (Delone and Mclean , 2003)

- Net Benefits: They refer to the extent to which IS are contributing to the success of individuals, groups, organizations, industries, and nations. (Petter et al 2008)

Delone and Mclean models have been used in a variety of IS contexts such as Egovernment (Wang and Liao, 2008; Jang, 2010; Jafari et al., 2011), KMS (Wu and Wang 2006), E-commerce systems (Molla and Licker 2001; Delone and McLean 2004;
Wang, 2008), e-learning (Hassanzadeh et al., 2012; Lin, 2007).

In ERP setting, several studies have tested and validated Delone and Mclean model. Indeed, in a survey conducted among 27 public organizations that implemented ERP system (SAP R/3) , Gable et al. (2003) studied the perception of staff from all the levels of these organizations regarding the impact of the SAP R/3 system. They suggested 27 items to measure four dimensions of ERP system success which are information quality, system quality, individual impact, and organizational impact.

In the same direction, Ifinedo (2006) used postal surveys of 44 private firms in Finland and Estonia. They extended the dimensions of success in the measurement model proposed by Gable et al. (2003) by adding Vendor/Consultant quality and Workgroup Impact. They suggest that these two dimensions were relevant in the discourse of ERP systems success.

Chien and Tsaur (2007) have used Delone and Mclean model in a study of 204 users of ERP systems at three high-tech firms in Taiwan. They suggested that system quality, service quality, and information quality are the most important dimensions for measuring post implementation ERP success.

\section{Satisfaction Based Models}

The literature review on the user satisfaction measurement has allowed us to identify two main references which are the Bailey and Pearson (1983) and Doll and Torkzadeh (1988).

Bailey and Pearson (1983) have proposed an Instrument of user Information satisfaction (UIS) by developing a semantic differential instrument of 39 items. Ives et al. (1983) based their research on the instrument of Bailey and Pearson (1983) and they retained 13 items in three dimension: EDP staff and Service, information product, knowledge or involvement. 
Doll and Torkzadeh (1988) have developed End-User Computing Satisfaction (EUCS) model based on the instrument of Ives et al (1983). They formed five elements: content (4 items), accuracy (2 items), format (2 items), ease of use (2 items) and opportunity (2 items).

EUCS have been tested in divers IS environment like online banking services, computerized accounting system or hospital information systems (Pikkarainen et al., 2006; Azleen and Zulkeflee, 2011; Dastgir and Mortezaie, 2012; Aggelidis and Chatzoglou, 2012).

EUCS instrument have been also tested in the ERP domain. Somers et al (2003) have been the first who have used the instrument of Doll and Torkzadeh (1988). Their empirical results of the survey, conducted by questionnaire sent to 407 users from 214 U.S. companies, indicated that the content, format and ease of use are the three main dimensions that contribute to satisfaction.

In a study conducted on a sample of 174 users of ERP systems in four Tunisian industrial groups, Mekadmi et al. (2008) have concluded that there are two major components of user satisfaction in relation to ERP systems. One related to satisfaction towards the ERP contents which includes reliability, completeness and usefulness and the other related to satisfaction towards ERP technological features represented by ease of use of the system and service quality.

\section{Use Based Models}

IS use has been studied as a behavior determined by social and cognitive variables, with the goal of finding variables that explain most of the variance in use (Burton-Jones and Straub, 2006). Two main models have emerged considering the use as a behavior. They are the technology acceptance model (TAM) (Davis, 1989) and the task technology fit model (TTF) (Goodhue and Thompson, 1995).

\section{Technology Acceptance Model}

People may use or not technology based on their belief that it will help them to do their job in a better way or not. Davis (1989) links this first point with the concept of perceived usefulness. He defines perceived usefulness as "the degree to which a person believes that using a particular system would enhance his or her job performance". He states also that even if a potential user believes that the use of a technology will improve its work, he can at the same time, think that the system is too difficult to use. In this case, the benefits derived from the use may be lower than what's expected. This is what Davis (1989) calls the perceived ease of use that will be defined as "the degree to which a person believes that using a system would be free of effort". Finally, Davis (1989) examines the relationship between use and attitudes toward technology based on the theory of reasoned action of Fishbein and Ajzen (1975). Both authors have developed a theory based on the concepts of belief, attitude and behavior. There are external variables that influence an individual's beliefs about the benefits associated with the execution of a behavior. These beliefs are, in turn, attitudes that will influence the intention to execute a behavior, and ultimately influence the behavior itself.

Several researchers have created new versions of TAM. Venkatesh and Davis (2000) proposed TAM2 as a new version of Technology Acceptance Model, they incorporated additional constructs spanning social influence processes (subjective norm, voluntariness, and image) and cognitive instrumental processes (job relevance, output quality, result demonstrability, and perceived ease of use). Venkatesh et al. (2003) proposed the Unified Theory of Acceptance and Use of Technology (UTAUT), which posits four key determinants of intention to use and behavior (performance expectancy, effort expectancy, social influence and facilitating conditions). Gender, age, experience, and voluntariness were significant factors that moderate the impact of the four key constructs on intention to use and behavior. In 2008, Venkatesh and Bala, combined TAM2 (Venkatesh and Davis, 2000) and the model of the determinants of perceived ease of use (Venkatesh, 2000), 
and developed an integrated model of technology acceptance called TAM3.

Technology Acceptance Model has been applied in various IT settings including online banking services (Mangin et al., 2011), business intelligence systems (Arvidsson and Pettersson, 2012), e-library systems (Jeong, 2011).

In ERP implementation environment, several studies have applied the TAM. Bueno and Salmeron (2008) used TAM to test the influence of five Critical Success Factors (CSFs) on ERP system acceptance. These CSFs are: (1) top management support, (2) communication, cooperation, (4) training and technological complexity.

Amoako-Gyampah and Salam (2004) extended the TAM model through the addition of one belief construct, shared beliefs in the benefits of an ERP system, and two external variables, training and project communication.

Sternad et al., (2011) argued that factors like organizational process characteristics, system and technological characteristics, Personal Characteristics and Information literacy have important influence on ERP usefulness and ERP ease of use. They also have a strong influence on the attitude toward using ERP system by ERP users in the routine (maturity stage).

\section{Task Technology Fit}

Focus on the intention to use or usage of IT raises a problem in voluntary environment. In the case of mandatory use of IT, the performance will depend increasingly upon technology task fit than utilization (Goodhue and Thompson, 1995). Goodhue and Thompson, (1995) proposed Technology to performance chain (TPC). This model gives a more accurate picture of the way in which technology, user tasks and utilization relate to a change in performance. The constructs of their model are:

- Technologies: Are viewed as tools used by individuals in carrying out their tasks.
They refer to the entire set of systems, policies and services provided by an IS department.

- Tasks: Are defined as the actions carried out by individuals in turning inputs to outputs. They are measured by task complexity, interdependence between tasks and hierarchical level of the user.

- User: May use technologies to assist them in the performance of their tasks. This construct include training, computer experience and motivation.

- Task Technology Fit : Is the degree to which a technology assists an individual in performing his or her portfolio of tasks this construct is measured by 8 criterions : data quality, locatability of data, authorization to access data, data compatibility, training and ease of use, production timeliness, system reliability and IS relationship with users.

- Utilization: Refers to the behaviour of employing the technology in completing tasks. This construct is measured by the frequency of use or the diversity of applications employed.

- Performance Impact: Refers to the accomplishment of a portfolio of tasks by an individual. This construct implies some mix of improved efficiency, improved effectiveness or high quality.

There are Various IT settings in which the model of task technology fit has been tested including learning management system (McGill and Klobas, 2009, Knowledge portals (Teo and Bing, 2008), mobile locatable information systems (Junglas et al 2008).

Through a case study conducted in two Australian public companies using ERP systems, Smyth (2001) has applied TTF while adding two constructs, Perceived usefulness and User Satisfaction for measuring ERP system success. He argued that TTF, perceived usefulness and user satisfaction are the three constructs that most satisfactorily indicate ERP success in an organisation. Another important aspect 
of the preliminary framework is the potential impact on perceived usefulness and user satisfaction of a range of organisational factors. These may include top management support, the presence of an ERP champion, organisational culture, and organisational politics. Smyth (2001) defined TTF for ERP as the extent of match between the facilities provided by the ERP package, the tasks undertaken by the users of that package, and the skills and attitudes of the individual users.

\section{Balanced Scorecard Based Model}

In an effort to better understand the tangible and intangible benefits derived from IT systems, several researchers have turned to tools like balanced scorecard of Kaplan \& Norton (1992). This model is based on the idea that performance should be evaluated from four main perspectives: financial perspective, customer perspective, internal process perspective and organizational learning perspective. With alterations in the framework of Kaplan \& Norton (1992), Martinsons and Davison (1999) applied balanced scorecards not only to assess the contribution of a specific information system or IS project, but also to evaluate the performance and guide the activities of an IS department or functional area. Four IS evaluation perspectives were proposed: User orientation perspective (Are the products and services provided by the IS department / functional area fulfilling the needs of the user community?), Business value perspective (Is the IS department /functional area accomplishing its goals and contributing value to the organization as a whole?), Internal processes perspective (does the IS department / functional area create, deliver and maintain its products and services in an efficient manner?) and Future readiness perspective (Is the IS department / functional area improving its products and services, and preparing for potential changes and challenges?).

As can be seen in the literature, Other researchers applied BSC in different kinds of IT/IS projects like Bremser and Chung (2005) in e-business, Bhagwat and Sharma
(2007) in SCM, Kim et al (2003) or Kimiloglu and Zarali (2009) in CRM , Lawson-Body et al (2008) in EGovernment.

In the case of ERP systems, Rosemann and Wiese (1999) were the first to use the balanced scorecard, they used it to evaluate the implementation and the use of ERP system. They proposed two balanced scorecards for these two steps by providing key questions that drive the identification of measures in each of the four balanced scorecard dimensions. For ERP implementation, the key questions are: What is the detailed cost of ERP implementation? (Financial), does the ERP software efficiently support the individual needs? (Customer), does ERP software improve the internal business processes? (Internal process), is the ERP software flexible enough to integrate future changes? (Innovation and learning). For ERP use, the key questions are what is the financial input necessary for achieving targeted performance level? (Financial), what benefits derive the company from a certain level of performance? (Customer), are internal processes effective and efficient in assessing level of performance determined by customer perspective? (Internal process), do ERP systems have enough potential for future customer needs? (Innovation and learning).

Chand et al (2005) proposed a framework which introduces automate, informate and transformate level benefits in all four Kaplan and Norton's balanced scorecard dimensions and provides goals that define the different types of benefits an organization can expect from ERP use.

Fang and Lin (2006) have used the four Kaplan and Norton's balanced card dimensions to evaluate the overall ERP performance in Taiwan public companies. They found that different corporate ERP objectives affected the post ERP performance and translated a company's vision and strategy through all its levels.

In a recent study, Velcu (2010) has used the four Kaplan and Norton's balanced scorecard dimensions to analyze the 
business performance derived from strategic alignment of ERP implementation stages in a sample of 88 Responding companies represented by CIO, CEO and CFO in the Nordic Countries.

\section{Research Methodology}

In order to understand the ERP system success perception, the qualitative research method based on a case study approach was chosen.

According to Yin (2003), the case study is a method of empirical research to study indepth a contemporary phenomenon within its context, especially when the boundaries between it and the object of study are not clearly delineated. This search method is based on several sources of data that must converge and the prior development of theoretical propositions to guide the collection and analysis of data. Direct contact of the interviewer and the interviewee implies a degree flexibility allowing the researcher to rephrase questions to clarify the meaning of words and expressions used and take into consideration non-verbal language of the interview at any time. The in-depth study of a case can provide a quantity of quality information on several aspects of the phenomenon.

We have targeted the managers of two companies because they should be the stakeholders of the ERP implementation with the most knowledge about the required business improvements.

At least four managers were interviewed in each company and a number of documents were collected as secondary data source. Indeed, in the company Alpha, The interviews were with the Chief Information Officer, the Management Controller, the Accounting Manager, and the Purchasing Manager.

In the company Beta, the interviews were with the Chief Information Officer, the Accounting Manager, the Purchasing Manager, and the Sales Manager. The interviews lasted between one and two hours.
We have chosen the three dimensions of success of ERP, information quality, information system and net benefits. Indeed, the two companies operate ERP system in mandatory settings. System use as a success variable is rejected. Also user satisfaction as a success variable is rejected because it is considered as an overarching measure of success (Sedera and Tan, 2005) and some items of user satisfaction appear both in information and system quality. Finally service quality was eliminated in this study because the two CIO interviewed are from the IS department and if asked about the service quality perception, it will make the findings wrong.

\section{Research Setting}

In what follows we will present a brief background of the two companies called Alpha and Beta in which we conducted the case study.

\section{Company Alpha}

Company Alpha, a subsidiary of a multinational company established in 13 countries, it is one of the major players in the area of construction in the kingdom.

In the interests of consistency and coherence, the multinational group started in 2000 the project of implementation of $\mathrm{SAP}$ in all its subsidiaries including Morocco's.

This project coincided with the acquisition of a plant in another city offering the opportunity to integrate it within the scope of implementation of SAP. For the sake of consistency beyond the borders of Morocco, it was necessary to develop a unique project for all subsidiaries, since each country had its own applications.

Before the implementation of SAP R3, multiple applications coexisted, we can cite CONCEPT for accounting and COSWIN for Inventory Management and CMMS. The existing softwares could cover just about $48 \%$ of business processes. After the implementation of SAP, the SAP coverage reached 95\%. The modules implemented were: Accounting, Controlling, Purchasing 
Stocks, Maintenance, Sales, Production and Quality.

\section{Company Beta}

Company Beta is one of the leading companies in the production and exportation of agricultural products in Morocco. This company is located in the south of Morocco and has more than 10 packing stations throughout the kingdom. It is presented in international markets such as North America, UK, Continental Europe, Scandinavia and Russia through the offices of its representatives.

Certainly, Beta like the other companies had gradually computerized most of its functions through softwares like Sage (purchase, sales, inventory and accounting) and other in-house applications such as AGIRH for human resource management, but overall this computerization could not manage the flow of information generated by the different services especially with the increase in production capacity and packaging. This situation was becoming intolerable especially for business managers, prompting the company to opt for the implementation of Sage ERP X3 in 2003 to replace the various applications related to business processes. The different modules installed were accounting, purchasing, sales and production.

\section{Results and Discussion}

An examination of data from interviews with managers of the two companies mentioned above has identified the perception of managers regarding ERP system success. Like stated above We'll be focusing on the three dimensions of ERP system success which are information quality, system quality and net benefits.

\section{Information Quality}

Interviewees from the two companies emphasized the quality of the information, stating that the information became more detailed, complete, reliable, relevant and updated.
Indeed, according to the accounting manager of Beta "products are analyzed independently and are reconciled with less detail. With the ERP system, all this is analyzed in detail". He added "The ERP system provides detailed information, for example, for each supplier, you can view the details of the transactions to date or the invoices that didn't result compared to payments or information related to the perception of maturity errors, as well as the amounts and methods of payment".

One of two CIO we met also stressed the information quality telling us that for his company, the information is complete. The management controller of Alpha stated "We must report regularly to the ERP system to provide us with a comprehensive overview of the various activities of the company in order to make management decisions at the right time".

ERP also generates reliable information. According to the management controller of Alpha "Before the ERP, trying to understand the overall situation of the company was tough because each unit had its own way of interpreting reality, but the ERP created a single version that cannot be questioned because everyone is contributing to the system and is at the origin of results". The CIO of Alpha added that "in case of error in the data, the ERP system allows traceability and ensures that the correction will be well done".

Relevance was among the qualities of information discussed by our interviewees. The ERP system generates information that is well suited to the needs of the organization. According to the CIO of Alpha, the production manager can make requests in the ERP system to see how stocks and orders evolve, this allows a better view of the production planning. He added "Before the ERP, many employees complained about their inability to generate statistics, numerical reports or other printings that they need, but with the arrival of the ERP system, the problem was solved". In addition, information from the ERP system procure to the sales manager the ability to 
perform cross analysis and establish statistics for detecting problems of dispersion of sales compared to orders, reducing turnover and delay and errors in deliveries.

Finally, the information is permanently updated. Accounting manager of Alpha stated that data about sales in quantity and in value became fully accessible instantly. In addition, this module provides the calculation of the COGS from the confirmation of the order.

He added, "After the expedition of an order, the system updates inventory records and sales history and transfers the financial data into General Ledger and Accounts Receivable files".

\section{System Quality}

The thematic analysis highlights some of the qualities of ERP system that are accessibility, reliability, integration and responsiveness.

As mentioned by interviewees, ergonomics is an important quality of system, it means that the system must be user friendly, simple to use and easy to access, allowing each user interacts with his desktop easily.

Reliability is a quality very stressed by the interviewees, CIO of alpha argued that if the system is buggy, it may cause blockages throughout the company and thereby influences the business continuity. With the absence of dysfunctions in the system users can spend more time doing something else.

Another quality mentioned refers to integration. As argued by CIO of Alpha, "before the implementation of the ERP system, we took the risk of repeatedly enter the same information to be stored in various files. The transition from one system to the other was not automatic where the use of Excel for data processing before was necessary, add to this the huge risk of error when downloading and transferring the data". Management controller of Alpha mentioned "Now with the ERP system, our factories and our subsidiaries are federated by a global network of integrated treatment management processes". According to Accounting Manager of Beta, "HR system works in conjunction with ERP system to enable seamless integration of all data to get the financial statements". Sales Manager of Beta argued that "the update of files, the development of a statement and the generation of documents relating to a customer order, such as invoices, pick lists, are types of activity resulting from a command input". According to the management controller Alpha "ERP allows us to better monitor budgets, adding that the budget process is facilitated by the sharing and standardization of data on which interact operational and management control."

The last quality raised in the interviews was the responsiveness, sales managers of Beta stated that "The ERP system allows faster orders processing. It is sufficient to fill in the boxes on the item code and quantity ordered for other information to be set automatically". According to the management controller of Alpha, "to meet the reporting requirements in a short time, the ERP system presents quickly fixed costs by type and activity".

\section{Net Benefits}

The results of our exploratory analysis show that the cost reduction, ease of sale transactions, budget tracking, inventory management, purchases controlling, communication and coordination improvement, reduced delays, user skills and productivity development, and the increase in their responsibilities are the main potential benefits provided by ERP systems.

Both CIOs have entrusted us that following the implementation of ERP, IT costs are reduced. The management controller of Alpha confirmed that the reduction of operating costs is obtained by streamlining processes. He added that the implementation of ERP reduces the Cost of goods sold (COGS). "The calculation of the COGS per product can provide answers to questions such as: Can we produce at this price level? What influences the cost 
mostly? Now, based on the standard unit cost, the COGS of each customer order is automatically calculated".

With regard to the reduction in the cost of labor, the accounting manager of Alpha stated that ERP has reduced workforce from 50 to 16 due to a reorganization of work since operations are entered only once.

Another advantage indicated by the sales manager of Beta is that the ERP system facilitates sales transactions and customer tracking. "ERP can track the state of the clients relationships progress and check if their demands were met on time".

ERP can also keep track of the budget, according to the management controller of Alpha, each manager is responsible for the budget. So, he can see the information related to the degree of achievement of budgets via the ERP system. "The system allows a monthly tracking of the budget, to make comparisons between what was done and what was expected, to report possible deviations and thus induce corrective decisions".

According to the purchase manager of Beta, ERP systems allow the controlling of the inventory level while taking into account the outstanding orders and thus suggesting to order quantities to maintain the level of stocks at the optimum "This can lead to greater efficiency in inventory management like a reduction of storage costs".

The ERP system enables control of purchases and expenses, According to the purchasing manager of Beta, the company can optimize the management of daily operations ranging from taking orders or purchase to cover bills.

CIO of Alpha said that the ERP system enables better communication and coordination facilitated by the use of a single, common vocabulary. He added "Before the implementation of the ERP system, we had to deal with more complex coordination problems due to a large number of entities and an extensive spatial and temporal dimension". The management controller of Alpha illustrated the advantage of communication and coordination by saying "The integration of the budget process in the ERP system induces an opportunity for rapprochement and cooperation between services".

According to respondents, ERP reduces delays such as delays in obtaining information on the status of receptions and turnaround of orders. The accounting manager of Alpha stated that the ERP system assists the managers in the elaboration of accounting and financial statements monthly, statements of accounts and statements of daily payments by bank. Moreover "Real-time processing of data reduces the time of fence, which is an enormous advantage compared to older systems". "Tedious Works of very long period were facilitated and carried out in record time".

According to the management controller of Alpha "Before, we had to collect data at the source and it is not uncommon to wait several days and involve several people for the synthesis of a situation involving several functions and systems".

According to the CIO of Alpha, The ERP system generates new knowledge through the bringing together of previously unconnected data. It brings users to increase their functional versatility adding that their skills are expanded and their work is enriched. CIO of Beta argued that ERP systems can also increase administrative productivity "The employee won't find any reason to delay an operation. All things are automated and integrated into a single database unlike what was before".

Another advantage is the increase in responsibility. According to the CIO of Alpha, the informational responsibility of employees increases due to the uniqueness of the information "since they must imperatively encode the right information at the right time so that the other actors involved in the same process are able to perform their work". In addition the system allows the identification of anyone 
responsible for an error "Through the possibility to follow the path of the information to find out who did what and when". Another respondent reported that users are aware that the use of ERP has made them more responsible and attentive. The input of incorrect information affects not only the one responsible for the input but also other users in the company.

\section{Conclusion}

This paper has started by presenting a synthetic review of literature on ERP systems success models. Four models of success were discussed: Delone and Mclean model (1992, 2003), user satisfaction, usage and balanced scorecard.

In order to study the perception of managers regarding ERP systems success in two Moroccan companies, a qualitative research method based on a case study approach was chosen. A total of eight managers were interviewed.

An examination of the data, collected from the interviews, showed that three dimensions of ERP system success. At information quality level, interviewees emphasized that information is more detailed, complete, reliable, relevant and updated .At system quality level, interviewees highlighted some criterions like accessibility, reliability, integration and responsiveness. At net benefits level, The results of our exploratory analysis show that the cost reduction, ease of sale transactions, budget tracking, inventory management, purchases controlling, communication and coordination improvement, reduced delays, user skills and productivity development, and the increase in their responsibilities are the main potential benefits provided by ERP systems.

However, it should be noted that this is a first exploratory reflection. This research should, indeed, be extended and verified by other empirical studies across a broad sample of companies from different industries and with different ERP systems implanted.

\section{References}

Amoako-Gyampah, K. \& Salam, A. F. (2004).

"An Extension of the Technology Acceptance Model in an ERP Implementation Environment," Information \& Management, 41(6), 731-745.

Au, N., Ngai, E. W. T. \& Cheng, T. C. (2002). "A Critical Review of End-User Information System Satisfaction Research and a New Research Framework," Omega, 30, 451479.

Bailey, J. E. \& Pearson, S. W. (1983). "Development of a Tool for Measuring and Analyzing Computer User Satisfaction," Management Science, 29(5), 530-545.

Bhagwat, R. \& Sharma, M. K. (2007). "Performance Measurement of Supply Chain Management: A Balanced Scorecard Approach," Computers \& Industrial Engineering, 53(1), 43-62.

Brasseur, C. (2005). Data Management: Qualité des Données et Compétitivité (Coll. Management et Informatique), Hermes Science Publications.

Bremser, W. G. \& Chung, Q. B. (2005). "A Framework for Performance Measurement in the E-Business Environment," Electronic Commerce Research and Applications, 4, 395-412.

Bueno, S. \& Salmeron, J. L. (2008). "TAMBased Success Modeling in ERP," Interacting with Computers, 20(6), 515-523.

Burton-Jones, A. \& Straub, D. W. (2006). "Reconceptualizing System Usage: An Approach and Empirical Test," Information Systems Research, 17(3), 228-246.

Chand, D., Hachey, G., Hunton, J., Owhoso, V. \& Vasudevan, S. (2005). "A Balanced Scorecard Based Framework for Assessing the Strategic Impacts of ERP Systems," Computers in Industry, 56, 558-572.

Chapman, C. \& Chua, W. F. (2000). 'Information Technology, Organizational Form, and Accounting,' In Proceedings of EIASM Second Conference on New 
Directions in Management Accounting: Innovations in Practice and Research, 193211.

Chien, S. W. \& Tsaur, S. M. (2007). "Investigating the Success of ERP Systems: Case Studies in Three Taiwanese High-Tech Industries" Computer in Industry, 58, 783793.

Dastgirn, M. \& Mortezaie, A. S. (2012). "Factors Affecting the End User Computing Satisfaction," Business Intelligence Journal, July, 292- 298.

Davis, F. D. (1989). "Perceived Usefulness, Perceived Ease of Use, and User Acceptance of Information Technology," MIS Quarterly, 13(3), 319-340.

Delone, W. H. \& Mclean, E. R. (1992). "Information Systems Success: The Quest for the Dependent Variable," Information Systems Research, 3(1), 60-95.

Delone, W. H. \& Mclean, E. R. (2003). "The Delone and Mclean Model of Information Systems Success: A Ten-Year Update," Journal of Management Information Systems, 19(4), 9-30.

Delone, W. H. \& Mclean, E. R. (2004). "Measuring E-Commerce Success: Applying the Delone \& Mclean Information Systems Success Model," International Journal of Electronic Commerce, 9(1), 31-47.

Doll, W. J. \& Torkzadeh, G. (1988). "The Measurement of End User Satisfaction," MIS Quarterly, 12(2), 259-274.

Dubarry, P. \& Bauvais, V. (1999). 'Retours D'expérience ERP,' CIGREF, Sept, 7-26.

Fang, M.- Y. \& Lin, F. (2006). "Measuring the Performance of ERP System - From the Balanced Scorecard Perspectives," Journal of American Academy of Business, 10(1), 256-263.

Fishbein, M. \& Ajzen, I. (1975). Belief, Attitude, Intention and Behavior: An Introduction to Theory and Research, Reading, MA, Addison Wesley.
Gable, G. G., Sedera, D. \& Chan, T. (2003). Enterprise Systems Success: A Measurement Model. In: S. T. March, A. Massey \& J. I. Degross (Eds.), Proceedings of International Conference on Information Systems, Seattle, Washington: ICIS Press (AIS E-Library),P. 576-591.

Goodhue, D. L. \& Thompson, R. L. (1995). "Task-Technology Fit and Individual Performance," MIS Quarterly, 19(2), 213236.

Hassanzadeh, A. Kanaani, F. \& Elahi, S. (2012). "A Model for Measuring E-Learning Systems Success in Universities," Expert Systems with Applications, 39(12), 10959 10966.

Ifinedo, P. (2006). "Extending the Gable et Al. Enterprise Systems Success Measurement Model: A Preliminary Study," Journal of Information Technology Management (JITM), 17(1), 14-33.

Ilias, A., Razak, M. Z. A., Rahman, R. A. \& Yasoa, M. R. (2009). "End-User Computing Satisfaction (EUCS) in Computerised Accounting System (CAS): Which the Critical Factors? A Case in Malaysia," Computer and Information Science, 2(1), 1824.

Ives, B., Olson, M. H. \& Baroudi, J. J. (1983). "The Measurement of User Information Satisfaction," Communications of the ACM, 26(10), 785-793.

Jafari, S. M., Ali, N. A. \& Sambasivan, M. L. (2011). "A Respecification and Extension of Delone and Mclean Model of IS Success in the Citizen-Centric E-Governance," Proceedings of the Citizen-Centric EGovernance IEEE International Conference on Information Reuse and Integration (IRI 2011) P.342-346.

Jeong, H. (2011). "An Investigation of User Perceptions and Behavioral Intentions towards the E-Library," Library Collections, Acquisitions, and Technical Services, 35(23), 45-60. 
Junglas, I., Abraham, C. \& Watson, R. T. (2008). "Task-Technology fit for Mobile Locatable Information Systems," Decision Support Systems 45 (4), 1046-1057.

Kaplan, R. S. \& Norton, D. P. (1992). "The Balanced Scorecard: Measures That Drive Performance," Harvard Business Review, $70(1), 71-79$.

Kim, J., Suh, E. \& Hwang, H. (2003). "A Model for Evaluating the Effectiveness of CRM Using the Balanced Scorecard," Journal of Interactive Marketing, 17, Spring, 5-19.

Kimiloglu, H. \& Zarali, H. (2009). "What Signifies Success in e-CRM?," Marketing Intelligence \& Planning, 27(2), 246 - 267.

Lawson-Body, A., Mukankusi, L. \& Miller, G. (2008). 'An Adaptation of the Balanced Scorecard for E-Government Service Delivery: A Content Analysis' Journal of Service Science, 1, 75-82.

Lee, Y. W., Strong, D. M., Kahn, B. K. \& Wang, R. Y. (2002). "AIMQ: A Methodology for Information Quality Assessment," Information \& Management, 40, 133-146.

Lin, H. F. (2007). "Measuring Online Learning Systems Success: Applying the Updated Delone and Mclean Model," Cyberpsychology \& Behavior, 10 (6), 817820.

Loshin, D. (2001). Enterprise Knowledge Management: The Data Quality Approach, Morgan Kaufmann Publishers.

Mangin, J. P., Bourgault, N., Guerrero, M. M. \& Egea, J. M. (2011). "Modelling Perceived Usefulness on Adopting on Line Banking through the Tam Model in a Canadian Banking Environment," Journal of Internet Banking \& Commerce, 16(1), 1-23.

Markus, M. L. \& Tanis, C. (2000). The Enterprise Systems Experience - From Adoption to Success, R. W. Zmud (Ed.), Framing the Domains of IT Research: Glimpsing the Future through the Past. Cincinnati, OH: Pinnaflex Educational Resources, Inc., 173-207.
Martinsons, M., Davison, R. \& Tse, D. (1999). "The Balanced Scorecard: A Foundation for the Strategic Management of Information Systems," Decision Support Systems, 25(1), 71-87.

Mason, R. O. (1978). "Measuring Information Output: A Communication Systems Approach," Information \& Management, 1(5), 219-234.

McGill, T. J. \& Klobas, J. E. (2009). "A TaskTechnology Fit View of Learning Management System Impact," Computers \& Education, 52, 496-508.

Mekadmi, S., Baile, S. \& Louati, R. (2008). "La Satisfaction de L'utilisateur D'un ERPContribution a L'étude D'un Modèle D'évaluation Avec la Méthode des Equations Structurelles," Proceedings of 13eme Congres de L'aim, Universite de Paris Dauphine, December, Paris, France, 13-14.

Molla, A. \& Luker, P. S. (2001). "ECommerce Systems Success: An Attempt to Extend and Respecify the Delone and Mclean Model of IS Success," Journal of Electronic Commerce Research, 2(4), 131141.

Nelson, R. R., Todd, P. A. \& Wixom, B. H. (2005). "Antecedents of Information and System Quality: An Empirical Examination within the Context of Data Warehousing," Journal of Management Information Systems, 21(4), 199-235.

Parr, A. \& Shanks, G. (2000). "A Model for ERP Project Implementation," Journal of Information Technology, 15, 289-303.

Pérotin, P. (2002). 'Mise en Place des PGI et Intégration Organisationnelle,' Proceedings of 7éme Congres de L'aim, 29 May - 1st June, Hammamet, Tunisie.

Petter, S., DeLone, W. \& McLean, E. (2008). "Measuring Information Systems Success: Models, Dimensions, Measures, and Interrelationships," European Journal of Information Systems, 17(3), 236-263.

Pettersson, D. \& Arvidsson, P. (2012). Usage of Business Intelligence Testing the 
Technology Acceptance Model on a BI System, Master Thesis Uppsala University.

Pikkarainen, K., Pikkarainen, T., Karjaluoto, H. \& Pahnila, S. (2006). "The Measurement of End-User Computing Satisfaction of Online Banking Services: Empirical Evidence from Finland," International Journal of Bank Marketing, 24 (3), 158 172.

Pitt, L. F., Watson, R. T. \& Kavan, C. B. (1995). "Service Quality: A Measure of Information Systems Effectiveness," MIS Quarterly, 19 (2), 173-187.

Poston, R. \& Grabski, S. (2001). "Financial Impact of Enterprise Resource Planning Implementations," International Journal of Accounting Information Systems, 2(4), 27194.

Rosemann, M. \& Wises, J. (1999). "Measuring the Performance of ERP Software a Balanced Scorecard Approach," Proceedings of the 10th Australasian Conference on Information Systems, 8(4).

Ross, J. W. (1999). "Surprising Facts about Implementing ERP," IEEE IT Pro, JulyAugust, 65-68.

SAP, (2010). "Implementing Entreprise Ressource Planning: Lessons Learned from the Front," A SAP White Paper, Available: http://www.sap.com.

Seddon, P. B. (1997). "A Respecification and Extension of the Delone and Mclean Model of IS Success," Information Systems Research, 8(3),24 0-254.

Sedera, D. \& Tan, F. (2005). User Satisfaction: An Overarching Measure of Enterprise System Success, P. Chau, J. Thong \& K. Y. Tam (Ed), Proceedings of the Pacific Asia Conference on Information Systems, Bangkok, Thailand: PACIS Press (AIS E-Library), 963-976.

Shang, S. \& Seddon, B. P. (2002). "Assessing and Managing the Benefits of Enterprise Systems: The Business Manager's Perspective," Information Systems Journal, 12(4), 271-299.
Shannon, C. E. \& Weaver, W. (1949). 'A Mathematical Model of Communication,' University of Illinois Press.

Smyth, R. W. (2001). "Challenges to Successful ERP Use," Proceedings of the 9th European Conference on Information Systems, June 27-29, Bled. Slovenia.

Somers, T. M., Nelson, K. \& Karimi, J. (2003). "Confirmatory Factor Analysis of the End-User Computing Satisfaction Instrument: Replication within an ERP Domain," Decision Sciences, 34(3), 595-621.

Sternad, S., Gradisar, M. \& Bobek, S. (2011). "The Influence of External Factors on Routine ERP Usage," Industrial Management \& Data Systems, 111 (9), 1511530.

Teo, T. S. H. \& Bing, M. (2008). "Knowledge Portals in Chinese Consulting Firms: A Task-Technology Fit Perspective," European Journal of Information Systems, 17(6), 557-574.

Thong, J. Y. L., Yap, C. S. \& Raman, K. S. (1996). "Top Management Support, External Expertise and Information Systems Implementation in Small Businesses," Information Systems Research, $7(2), 248-267$.

Velcu, 0. (2010). "Strategic Alignment of ERP Implementation Stages: An Empirical Investigation," Information \& Management, $47,158-166$.

Venkatesh, V. \& Bala, H. (2008). "Technology Acceptance Model 3 and a Research Agenda on Interventions," Decision Sciences, 39(2), 273-315.

Venkatesh, V. \& Davis, F. D. (2000). "A Theoretical Extension of the Technology Acceptance Model: Four Longitudinal Field Studies," Management Science, 46(2), 186204.

Venkatesh, V., Morris, M. G., Davis, G. B. \& Davis, F. D. (2003). "User Acceptance of Information Technology: Toward a Unified View," MIS Quarterly, 27(3), 425- 478. 
17 Journal of Enterprise Resource Planning Studies

Wang, R. Y. \& Strong, D. M. (1996). "Beyond Accuracy: What Data Quality Means to Data Consumers," Journal of Management Information Systems, 12(4), 5-33.

Wang, Y.- S. (2008). "Assessing ECommerce Systems Success: A Respecification and Validation of the Delone and Mclean Model of IS Success," Information Systems Journal, 18(5), 529557.

Wang, Y.- S. \& Liao, Y.- W. (2008). "Assessing Egovernment Systems Success: A Validation of the Delone and Mclean Model of Information Systems Success," Government Information Quarterly, 25(4), 717-733.

Wu, J.- H. \& Wang, Y.- M. (2006). "Measuring KMS Success: A Respecification of the Delone and Mclean Model," Information \& Management, 43(6), 728739.

Yin, R. (2003). Case Study Research: Design and Methods, Thousand Oaks: Sage Publications. 